\title{
Disruptive Technologies and the Sport Ecosystem: A Few Ethical Questions
}

\author{
Migle Laukyte \\ Law Faculty, Pompeu Fabra University, 08005 Barcelona, Spain; migle.laukyte@upf.edu \\ Received: 30 August 2020; Accepted: 29 September 2020; Published: 2 October 2020
}

\begin{abstract}
The paper addresses the impact of disruptive technologies on the sport ecosystem, represented by four constitutive elements: athletes, coaches, judges, and fans. In particular, the paper argues that to understand the changes introduced by Artificial Intelligence, biotechnologies, and other disruptive technologies, we have to look at this sport ecosystem as a whole and ask ethical questions related to how each of these elements-and not just the athlete-is affected by them. The paper discusses some of the real-life applications of disruptive technologies that are being currently introduced within different sports and works out their most critical aspects both in terms of positive and negative impact on the sport ecosystem as we know it.
\end{abstract}

Keywords: disruptive technologies; Artificial Intelligence; biotechnologies; virtual reality; sport ecosystem

\section{Introduction}

Since last century, we are observing a transformation of our societies caused by disruptive technologies, such as Artificial Intelligence (AI), robotics, biotechnologies, nanotechnologies, and others. These technologies are termed disruptive because they substantially modify the usual way of operating. This transformation is gaining in speed, breadth, and profundity in terms of its economic, social, legal, and political effects on different ecosystems. Ecosystem, for the purposes of this paper, is understood as a set of living and interconnected elements existing within a defined environment. This paper is dedicated to exploring these effects on the ecosystem of sport. (Sport is a very broad term, and I will therefore refer to sport as a professional sport, usually part of the Olympic games, and not as a leisure activity. I will also refer to sport as an activity that represents many of our values, such as endurance, fairness, justice, and courage. On the terminological difficulties to define sport and distinguish it from games and play, see the overview provided in [1]).

In particular, I will argue that in order to understand the disruptive transformation of sport, (In this context, disruptive transformation of sport refers to a new kind of sport that is based on the use of disruptive technologies: the technology is a game changer that pushes sport to a new level, as it happens with athletes that have artificial limbs or with Big Data that enables the whole sport ecosystem to have access to information (data as such, its correlations, causations, etc.) neither known nor available before. Therefore, although technology has always been part of sport history, the disruptive technologies discussed in this paper mark a "before" and "after."). we cannot only focus on the athlete and the disruptiveness of technologies that she is undergoing and technological challenges that she is facing; instead, what we have to do is to look at a wider picture, that is, we have to adopt a holistic approach and observe the wider ecosystem of professional sport, which includes not only the athletes, but also judges, coaches, and the public in general, besides numerous other stakeholders.

In fact, a holistic perspective provides us with the wider spectrum of the impact of disruptive technologies on sport: It is not only the athletes who are facing new biotechnological challenges in the form of legal and illegal drugs, physical and cognitive enhancement, and the use of biomaterials in 
injury treatment, but the whole professional sport ecosystem is dallying with possibilities offered by AI, robotics, augmented and virtual reality, and other technologies. This paper is dedicated to addressing the professional sport ecosystem in the 21st century or, as they say in sport terms, see how this ecosystem scores in playing with—against?-disruptive technologies: Are we, as humans, winning or losing? Are we moving to partially or completely human-less sport or just giving a new meaning to what is (or should be considered) human within professional sport? Are disruptive technologies useful or harmful?

To address the challenges of these disruptive technologies to the sport ecosystem, the paper is organized as follows: In Part 2, I elaborate more on the sport ecosystem and its four constitutive elements, namely, the athlete, the judge, the coach and the fans. It is a very simplified version-there are many more elements, and the aforementioned elements could be further specified as, quite often, the coach is not a single person but a team of professionals that range from coach, her assistants, physical trainers, etc.,-yet sufficient to illustrate the point of the paper. In the third part, I look at how each of these components are affected by some of the disruptive technologies: The main idea is to show that if we usually associate sports with biotechnologies, that is no longer true as the challenges and changes come from a much wider gamut of innovation, such as AI and virtual reality (VR). How they change sports as we know it and what their broader ethical implications are is a central question of the fourth part of this work. The paper ends with concluding remarks.

\section{Sport Ecosystem at a Glance}

The sport ecosystem has four components: The athlete, the judge, the coach, and the public. These elements represent simplified versions of complex realities and are therefore just generalized illustrations that provide us with the idea—but not with the scientifically sound clarification—of what each of these elements represents.

For example, the athlete is understood both as a young person who is at the beginning of her career and also as a professional at the highest peak of her physical performance. Further, she can be an individual athlete but also a member of a team. In other words, anyone who is about to or is already dedicating herself to professional sport. For the purposes of this paper, I will adopt the definition suggested by Araújo and Scharhag, according to whom the athlete is a person who satisfies the following criteria: "(a) to be training in sports aiming to improve his/her performance or results; (b) to be actively participating in sport competitions; (c) to be formally registered in a local, regional or national sport federation as a competitor; and (d) to have sport training and competition as his/her major activity or focus of interest, almost always devoting several hours in all or most of the days to these sport activities, exceeding the time allocated to other professional or leisure activities" [2] (p. 6). This definition stresses the commitment to sport, the rivalrous nature of this commitment, formalized belonging to the category of athletes, and the prevalence of sport activity over any other activity in her professional life.

The second element of this ecosystem is the coach who is a complex figure that goes beyond any definitions and frameworks. Indeed, if the idea of an athlete is built around physical performance, the idea of coaching goes further than just training and advising the athlete. It relates to pedagogy, social skills, psychology, medicine, and many other domains: That is why perhaps the most appropriate definition of coach is someone who is directing "the coaching process and all that that implies" [3] (p. 60), which means that coaching as an activity does not have limits nor established boundaries. In addition, the coach, more often than not, becomes part of the private sphere of an athlete's life, if this is not already the case, as happened with many elite athletes, such as tennis player Andre Agassi who was initially trained by his father Emmanuel Agassi, tennis player Rafael Nadal who, until 2017, was coached by his uncle Antonio Nadal, or football player Lionel Messi, who as a child, joined a local football club where his father trained him. (The coaching sometimes enters the personal sphere also through marriage, as happened to runner Kim Collins who married his coach Paula Collins. However, building family ties sometimes ends in divorce as well, like it happened to swimmer Katinka Hosszú 
and her coach Shane Tusup. It is not the purpose of this paper to present the variety of possible coach-athlete relationships, but just to show that this relationship might have further complications caused by the difficulties of keeping a distance between professional and personal life, and therefore adds additional complications to finding a definition for sport coaching as a profession).

The third element-judge- has many forms: She can literally be a judge who stands up at the end of the exhibition and gives grades, as it happens in figure skating, a referee in football or boxing who blows the whistle and is the ultimate authority on the field or boxing ring, or also a more invisible authority like it happens in race walking when we usually do not even see the judges. (The terminology of how these figures are called strongly depends on the specific sport; however, I use the term judge and referee interchangeably throughout this article). This element represents, then, this broad category of professionals who are entitled-thanks to specific studies and certification procedures-to evaluate the athletic performance and even disqualify the athletes in the most extreme of cases. Needless to say that their evaluations are more often than not subject to public disagreements and discussions, especially in such sports where evaluation parameters are not as clear and comprehensible as figure skating or artistic swimming, whereas in other sports, such as speed skating, rowing, or fencing, challenges to their decision do not arise as often (although they surely do from time to time).

Last, but not least important, is the fourth component, that is, the fans of a specific sport. There are many ways to look at fandom: Fandom indeed is some kind of: "[ ... ] a multidimensional concept, with cognitive, affective and behavioural domains" [4] (p. 66), and this element is the most inclusive of four elements. For the purposes of this work, the fans are seen as assiduous consumers and committed indirect participants of athletic performance: This involvement is what differentiates fans from mere observers, who watch but do not "get involved in" a particular sport. Perhaps what sport means for a real fan could be understood best through the words of Roland Barthes, who argues that: "everything that is happening to the player is also happening to the spectator. But whereas in theatre the spectator is only a voyeur, in sport he is also one of the actors", and therefore, the fans, who watch the sport, are not just engaged but experience something more: "[ ... ] watching is not only living, suffering, hoping, understanding, it is also saying it, with the voice, with the gesture, with the expression, it is taking the whole world to witness, in a word, it is to communicate" [5] (p. 82).

The relationships between these four elements are far from stable: I assume the ideal scenario where the athletes perform, coaches train, judges evaluate, and fans support the athlete, although there is much more to that than just this ideal model of interaction. For example, the whole business part of sports that revolves around the athlete and fans in particular, such as big sportswear companies like Nike or Adidas, and also the broadcasting companies that have sports media rights, insurance companies, legal firms, etc. (The business part, however, is briefly addressed in Part 4). Other examples of elements that are not addressed here are the organizational managerial parts related to the professional leagues and international sport organizations, such as the International Olympic Committee or FIFA, or referee associations and schools. However, as far from reality as this model can be, it is sufficient to illustrate the point of this work, namely that disruptive technologies affect the sport ecosystem and not just the athlete: This disruptiveness reverberates through all its elements. To be sure, this reverberation affects the athlete particularly and there are no doubts about that, but it also affects other elements which are strongly interrelated and interdependent. This is why to focus on the athlete only is to tell just a part of the story: This paper wants to contribute to presenting a more complete version of it.

In the following Part 3, I present some of the changes introduced by disruptive technologies within the sport ecosystem and, in particular, focus on how some specific examples of disruptive technologies affect each element-athlete, judge, coach, and fans-so as to address some of the ethical questions and link these questions to the wider set of concerns that disruptive technologies are bringing forward in sport (Part 4). 


\section{Sport Ecosystem and Disruptive Technologies: Uses and Examples}

The history of sport is also the history of people's hunger to overcome their physical and mental limitations as to what the human body is and what it can do. For some, sport represents a competition to establish who among humans is best in harnessing the world and giving it to all mankind [5]. In the process of doing so, humans have used many means. The 20th century was a century not only for the spreading of sport as both a professional and leisure activity [1], but also the century of technological breakthrough. How these two areas-sport and technologies-interact is the focus of this section. In particular, I address some of the various ways disruptive technologies affect each element of the sport ecosystem.

\subsection{Enhancing Athletes}

In the case of the athlete in particular, the means to enhance-or dope-yet we use the term "enhancement" as more morally neutral [6] — the human body has grown in number and complexity. (Bearing in mind the variety of biotechnological possibilities for athletes, this paper focuses on selected examples). For instance, the possibilities for genetic manipulation that range from simply increasing human potential to turning a person into a transhuman with superhuman abilities [7] or cognitive enhancement, that could take the form of cognitive enhancers or transcranial stimulators [8], represent just a small part of how the human body and mind could be modified and "updated." Indeed, enhancement is part of sport and, in this context, sport is a laboratory of ethical issues related to human enhancement [9] and there are many opinions whether these and other physical and cognitive enhancement techniques should be allowed or not. On the one hand, stand the pro-enhancement defenders, according to whom athlete enhancement is a part of sport and a place where human limitations can be challenged (an "instantiation of the essence of sport" [9] (p. 45)), whereas on the other hand, there are the opponents, bioconservatives, who consider that enhancement clashes with the idea of the normalcy of a human athlete, and in particular, disagree with substantial or "transformative changes" that alter the athlete's individual experiences and feelings [9]. However, when neither shortnor long-term effects on athletes are all that clear, cautionary principles should apply, yet at the same time that does not mean that these techniques should be prohibited altogether $[8,9]$.

What is not prohibited, but on the contrary supported, is the use of biomaterials in the medical treatment of injuries and other medical treatments that aim to re-establish, rather than to enhance, the function of an athlete's body. That is especially so if the injury or illness is more often among athletes rather than among non-athletes, as it is in the case of injuries to tendons, knees, back, or brain damages caused by contact sports such as rugby or football. (There are also the bioethicists and philosophers who argue that some of the contact sports are morally unacceptable because of the brain injuries they can cause: the counterarguments to such claims are related to personal autonomy and freedom, pre-emptive paternalism, and practical difficulties to limit the exercise of these sports, among many others [10]. From this perspective, biotechnology and biomaterials could be seen as additional arguments in favor of leaving contact sports as they are).

However, the biotechnology and neurotechnology's sport conundrum push the debate on the wider scale where the future developments are still to be discovered and enhancement does not refer only to the human body as such, but also to the tools it will use in its performances. (However, we could also talk about both, because some of the new materials can be used for human body and for high-performance athletic equipment: for example, ultra-high molecular weight polyethylene can be used for the base layer of the ski, but also for artificial hip and knee implants. Therefore, the division between what materials we use as part of tools and what we implant within human bodies are blurring. For more about this, see [11]). For instance, Biodesign, a project of Puma and MIT aims to discover "how the next generation of athletic footwear, apparel and wearables can adapt in real-time by using living organisms to enhance performance" [12]. The project researchers are working on shoes with personalized ventilation to keep the right temperature for the athlete's foot with deep learning insoles that would use bacteria to measure the athlete's fatigue. 
In this section, I have looked at some, among numerous, possibilities that biotechnological research provides athletes with: the spectrum of what the athlete could do or use so as to improve her performance is overwhelming, and the limits are not within the realm of possibilities, but rather within that of resources. However, the athlete is not alone: the sport ecosystem contains other elements which, although differently, are also subject to a variety of opportunities and contingencies that were unknown just 20 years ago.

\subsection{Advising the Coaches}

Disruptive technologies for coaches could be basically reduced to two words: data analytics, which automatically refer us to the field of Artificial Intelligence (AI). Having athlete's data, thanks to sensors and wearables in real time, (Any reference to sensors and wearables, as many other technologies addressed in this paper, inevitably leads to questions concerning privacy and personal data protection. However, these questions are not part of this paper). and having tools to process the data so as to extract new information and to predict the possible outcomes is what the AI-based algorithms are being used for in many business, industrial, and other sectors: sport is no different. (Furthermore, in the field of football, the engineers are moving from data analytics to skills analytics that permits to analyze a player's skills, her progress, create skill standards, and use the data in other ways to train the player. For more about this tool, see ISOTECHNE (https://www.isotechne.com/)).

For a coach to have this AI-based support is enormously helpful in the decision-making process: it helps to calculate the training schedules on the basis of previous injuries, time between competitions, time zones, and jet lags, to identify when and under what circumstances the athlete is not performing at her best and many other parameters: this is why we started talking about "AI- augmented coaching" [13].

However, many AI-based tools are explicit as to their advisory—and not substitutional—role in the training of an athlete: For example, the system HumanGoTM's AI Coaching Assistant (For more about this system, see https://humango.ai/\#coaches.) is described as one which simplifies the job of the coach, but leaves her to decide ("You are the one in control").

Yet there are also AI that could be seen as substitutes of the coach: HomeCourt application, (For more about HomeCourt app, see https://www.homecourt.ai/.) developed together with the NBA for basketball players, tracks player's skills, such as shots and provides detailed information about each of them, thus giving the athlete real-time feedback on her performance. In this case, for example, the player does not need a human coach to tell her what is wrong with her shots as the coach is AI and it neither errs nor gets distracted.

AI-augmented coaching opens the door not only to a new way of coaching professionals, but also to a new way of scouting and recruiting new talent. Whereas the coach is still the person with "an eye" to identify the potential, her evaluation and decision-making starts to be supported by algorithms that permit to use a variety of data and metrics and forecast future successes [14]. Indeed, the research shows that although coaches' personal assessments meet objective physical criteria, that happens only with the highest- and lowest-performing future athletes, whereas when concerned with similar-level athletes, it becomes very divergent [15]. It means that the coaches are good at identifying a super talent, yet not that good in choosing from more or less equally talented children. In this context, the AI-based support could be especially helpful.

\subsection{Supporting the Judges}

At first glance, it might seem that the task of the judge is the easiest to substitute by technological means: The task of referees in some of the sports is easily subject to errors, although at the same time, it requires high precision and accuracy (i.e., running or swimming). Indeed, photo finish technologies—as well as false start detection technologies—-provide 1/1000th accuracy for running, cycling, rowing, race walking, and other sports where the competition to cross the finish line first is the 
overall objective of the performance. (For more information about these technologies, see, for instance, the products of Lynx at https://www.finishlynx.com).

Other sports, too, are subject to technological assistance, such as Video Assistant Referee (VAR) in football. However, the rules of its use clearly establish that the referee in the field is the one who takes the decision, and only once the decision is taken, can she in specific cases of "clear and obvious error" or "serious missed incident" relating to penalties, goals, or red cards, ask for the assistance of VAR. (The International Football Association Board (IFAB) include among the principles of VAR use, that: "The referee must always make a decision, i.e., the referee is not permitted to give 'no decision' and then use the VAR to make the decision; a decision to allow play to continue after an alleged offence can be reviewed and that only the referee can initiate a 'review'; the VAR (and other match officials) can only recommend a 'review' to the referee." The rules of VAR's use are available online: https://www.theifab.com/laws/chapter/38/section/113/). That is to say that technological assistance is used if and only if the referee requires it, but she can also omit its use-there is no obligation on her part to use VAR. However, can sport continue like this? Moreover, what about other sports where the point is not speed or scoring, but aesthetics?

Indeed, not all sports can be reduced to precision, scoring, and calculation, as many sports require subjective evaluation of performance, like it happens in figure skating or synchronized swimming. Although there are established criteria, rules, and point attribution systems, there is still a lot of freedom left for judges to evaluate, for example, how a dancer on the ice satisfies the requirement of "The personal, creative, and genuine translation of the rhythm, character and content of music to movement on ice" [16]. Furthermore, many researchers have shown that there are serious problems with the manipulation of scores [17], and additionally, the overall system of judging is becoming more and more complex (synchronic swimming has three panels of judges, five judges in each panel, and each panel responsible for grading execution, impression, and elements [18]). (We have to bear in mind that in the case of synchronic swimming, there are further changes in time (performances are shorter) and it requires more acrobatic skills and more sophisticated performance [18]. Needless to say, these changes make judgement much more challenging).

Therefore, and differently from the coach, the human judge herself might see sense in asking for AI support in making (or confirming) her decisions: The International Gymnastics Federation (FIG) planned to use "Judging Support System" developed by Fujitsu during the Olympic Games of 2020 in Tokyo (Japan). (The video explaining the functioning of this system is available online at the following link: https://futurism.com/ai-judges-score-gymnastics-2020-olympics (accessed on 2 June 2020). For more about the Fujitsu system, see https:/www.fujitsu.com/global/about/resources/ news/press-releases/2019/1015-02.html). This system provides an almost real-time data of an athlete's performance, and after confronting this data with the gymnastics standards, issues a score. This score is not mandatory for human judges and yet it could be extremely helpful, especially in those cases where the (human) judge's decisions are challenged.

\subsection{Involving the Fans}

Disruptive technologies offer new possibilities for the fans, who want to follow their favorite sport as closely as possible. Indeed, $69 \%$ of fans claim that emerging technologies have improved their ways of sports consumption [19].

One of the most promising experiences that the disruptive technologies offer is the different applications based on augmented and, in particular, virtual reality (VR), (Virtual reality is also used to train the athletesVirtual reality is also used to train the athletes.) that permits fans to become more involved in the competition or the game. (Augmented and virtual reality are evolving into different kinds of combinations enhanced with additional elements that are named as mixed reality and extended reality. However, these applications are still under-developed and are therefore not addressed in this paper). For instance, iRacing application used together with a VR headset takes the person directly into the driver's seat of the NASCAR race, which makes a person experience the race much more than just by observing it on TV. 
Other AI-based tools for fandom are: ADIDAS footballs with NFC (near-field communication) chips that link the ball to fans' mobile phones; match prediction tools based on machine/deep learning and neural networks, such as Kickoff.AI and FootballScoreChat (For more about Kickoff.AI, see https: //kickoff.ai/; FootballScoreChat is available online: http://www.footballscorechat.com/.) and Snaptivity (For more about Snaptivity, see https://snaptivityapp.com/.) that, thanks to AI-empowered robotic cameras, catches genuine fan reactions during matches. There are also many other tools that aim to address the motivations that drive fans, such as the search for entertainment, escape, connecting, and others [20].

\section{Ethical and Legal Implications of a Technologically-Advanced Sports Ecosystem}

In this section, I look at some of the ethical questions that the disruptive technologies described in Part 3 give rise to. I deliberately separated this part from the previous one so as to stress, on the one hand, the range of an ever growing number of technological possibilities (Part 3), and affront it with, on the other hand, the continuity and persistence of some-different in form, yet similar in their essence-questions that these technologies cause both in terms of positive and negative impact on the sport ecosystem (Part 4).

\subsection{Enhancing Athletes: Between Faster Recovery and Cyborgization}

The "cyborgization of sport" that refers to continuous human enhancement in sport is a phenomenon that has been under scrutiny for a while and has moved the debate on admissibility of these enhancements to the realm of equality of opportunity and justice and their clash with personal autonomy and unjustified paternalism [21].

The impact of biotechnologies is the most evident on athletes, and in particular, their bodies. Think about the use of biomaterials in medical treatment: To many extents, the impact is positive because the athletes are given a chance to recover and heal bodily injuries that, in other circumstances, or with less reliance on innovation, could have lasted longer or had longer-term consequences on their performance, or could have prevented them from continuing their careers altogether. One example, among many, is tennis player Rafael Nadal whose recovery from knee injury was accelerated by the use of Nadal's own plasma enriched with growth factors that regenerates tissue in practically half the time than other conventional medical treatments would have [22].

At the same time, however, Rafael Nadal himself stressed that: " $[\ldots$ ] sports medicine is not the only aspect that has to change to improve player conditions. Our job has to change. The tournaments and the Association of Tennis Professionals (ATP) circuit also have to change a little bit. There are too many weeks. The circuit is too long and there are too many matches" [23]. From the perspective of a high-performance athlete, we can see a vicious circle taking shape: On the one hand, the time to recover from an injury is reduced thanks to technologies; on the other hand, the pressure on the athlete for performance increases as technologies solve "the inconvenience" of an injury and puts the athlete back on track much sooner than she would-under less technologically-advanced circumstances-have returned. This return means faster, more competitive, and more consuming performance and, consequently, more chances of injury, that again, might (or not) be solved with the help of the advancements in biotechnological research.

In addition, in these cases, we have to question the informed consent of the athlete: How compatible is this informed consent with the social, financial, emotional weight to get back to professional competition as soon as possible? The pressure on professional athletes are unknown to the majority of us, yet leaving these questions for her to decide — thus defending the value of personal autonomy—risks making us "close an eye" to the questions that ask for our full alertness and engagement.

Biomedical research also puts on the table the question of transhumans, cybersportspersons and the like $[7,24]$, that places the debate on a wider scale and leads to such questions as whether and to what extent these physical and cognitive transformations of human body and mind are acceptable and compatible with human dignity and the established social, ethical, and legal values. Human health 
has always been the guiding principle in these debates; however, as already mentioned above, in many cases, especially in cases of disruptive biotechnologies, the effects of these enhancements on human health are not yet known and clear, and this is why the caution is acceptable, but prohibition is not [8]. From this perspective, the athletic transhumanism and cyborgization could be seen as a continuation of the pre-existing philosophical debate on doping: although technologies differ, evolve, and change, the essence of athlete transformation and the ethical questions it gives rise to remain the same. The philosophical arguments against doping have been found insufficient by many $[25,26]$ and the normative anti-doping measures - such as the World Anti-Doping Code issued by the World Anti-Doping Agency-are often unable to withstand philosophical scrutiny [27].

This is why the focus is on the individual's autonomy and choice: Should she be free to decide? Some athletes raise their voice, arguing that legalizing these enhancers would mean requiring them to take them so as to be competitive with respect to other athletes who took them already, but most importantly, that these drugs take away something from the athlete. One of them expressed this feeling in the following words: "In a drugged world, the victors would still claim the spoils, but the intangible rewards, the pride in success, the sadistic joy in hard work, would fade away. There would always be a question in the back of my mind-was it me or the drugs?" [28].

Last, but not least, and also related to the physical and cognitive enhancement of the athletes, there is an ethical question on the availability and accessibility of the biomaterials-based products for all athletes and the fairness of competition when this accessibility is not guaranteed. Such questions are not new: Many studies have shown the relation to the wealth of country and its performance at both Paralympic and Olympic competitions [29]. From this perspective, biomaterials are just another example of inequality of accessibility to resources and enduring the divide between athletes of rich and poor countries. Disruptive technologies, in this sense, just stress and confirm the pre-existing ethical problem of fairness in sport.

\subsection{Advising the Coaches: Discreditation or Support?}

To address ethical implications related to the use of disruptive technologies in coaching practice, let us imagine that a football coach uses an AI-based system, that advises her who she should recruit to enter a children's football team. The system is fed with data on the best, the most resilient, the fastest, and the most successful football players in the world, and on the basis of this data, the system elaborates the profiles and predictions as to the characteristics of the next champion. Many of the best players today come from poor backgrounds (Cristiano Ronaldo, Zlatan Ibrahimovic, Diego Armando Maradona, Luis Alberto Suarez Diaz, Neymar Jr., and many others), and the majority of most successful foreign professional football players come from Brazil and other South American countries. Perhaps a professional football coach does not need an AI system to know this, yet there might be many more metrics she is not aware of, such as height, weight, other physical conditions, speed, reaction time, different causation links between these parameters, and so on and so forth. Therefore, a coach might need AI to assist her in identifying the children that fit the pattern of a champion: The human coach does not have a sufficient cognitive capacity to take into account and process all the available data. In fact, when a coach has 300 highly promising future football players in front of her, she has to make a decision, and an AI-based system could help in doing that.

The situation is different if the coach is completely substituted by AI and is taken out of the loop: The question is whether it would be right to entrust AI with these decisions. This reasoning of the role that AI should play in (human) decision-making that affects other human beings reflects the one made by the High-Level Expert Group on AI that was set by the European Commission to elaborate "Ethics Guidelines for Trustworthy AI" [30]. These Guidelines stress the importance of several key requirements that ensure this trustworthiness, among which is the human agency and oversight: "AI systems should empower human beings, allowing them to make informed decisions and fostering their fundamental rights. At the same time, proper oversight mechanisms need to be ensured, 
which can be achieved through human-in-the-loop, human-on-the-loop, and human-in-command approaches" [25].

For our purposes, the most relevant approach among the aforementioned is the last one, human-in-command approach. (The other two approaches are explained as well: "Human-in-the-loop" refers to the possibility that a human being could intervene at any point during the decision-making process made by the system; "human-on-the-loop" refers to the possibility of human intervention at any moment during the design stage of the system and also a possibility to monitor its functioning). This means that the human being should be able "to oversee the overall activity of the AI system (including its broader economic, societal, legal and ethical impact) and the ability to decide when and how to use the system in any particular situation" and that this ability to decide "[ ... ] can include the decision not to use an AI system in a particular situation, to establish levels of human discretion during the use of the system, or to ensure the ability to override a decision made by a system" [25]. Coming back to our example, if we want to use AI ethically, we should let the coach use the AI only to help her make decisions, but not require her to follow these decisions blindly. She has to be the one who decides whether to take the AI suggestion on the future athlete into account or discard it, but never should she be obliged to follow it, especially when she disagrees with it. In other words, human judgement should prevail over the $\mathrm{AI}$ if the use of $\mathrm{AI}$ is compliant with ethics.

Perhaps this brings us back to the very beginning: If the coach is to decide in any event, then why should she use the AI-based system at all? As there is so much subjectivity involved in evaluating the future athletes (although objective criteria matter too), she might use AI to justify and legitimize her decision, but this only works when AI confirms her assessment. The next question is whether it would not be correct to let the parents of the young athlete or the young athlete herself see the coach's evaluation and compare it to the AI's: This is how we could guarantee more transparency to the process where prejudice and bias could—and usually do-play a big role in deciding another person's future [31]. At the same time, by allowing the revision of a coach's decision, we also open the door to her discreditation in those cases when her and AI's evaluations differ.

\subsection{Supporting the Judges: Promoting Errorless Refereeing or Discrediting Human Judgement?}

As already mentioned above, AI-based tools to support a referee's work promises an errorless competition and freedom from manipulation in evaluating aesthetic and artistic performances of athletes. However, many sports do not embrace these technologies as much as we might have expected: For example, the rules of race walking explicitly establish that their "judgements shall be based on observations made by the human eye" [32] (p. 6). This shows the reluctance of some of the sports to use technological means—not to talk about disruptive technologies, such as AI—in judging athletes.

These rules also illustrate indirectly the shortcomings of human judging. For example, they ask the judges not to have preconceptions as to future performances of the athlete, in particular if she is making mistakes ("do not prejudge [athletes] for the next race" [32] (p. 12)), then invites judges to act independently and impartially, and not let others influence their judgement. Are not these all reasons why race walking (and many other sports as well) should implement AI-based judge-supporting or even judge-substituting systems in the first place? Perhaps the biggest obstacle to do so is the lack of trust in technologies and the fact that many of them are still underdeveloped in terms of their human-like abilities. For example, to let the robot be a referee in the football match would mean to let it-besides many technically measurable, and therefore robotically solvable, questions-interpret human intentions. So as of today, social robotics and robotics in general are not sufficiently advanced to be able to do that.

As to the judgments on aesthetics and artistic performance in some of the sports, there is a huge question mark not only as to the ability of AI to interpret and value these parameters, as much as a human refusal to submit one's performance to machine-based evaluation. What does an AI or a robot know about aesthetics, beauty, ability to communicate one's feelings and emotions through movement? Sport is done by humans for humans. Taking a human judge out of the loop means, to a certain extent, 
dehumanizing sport and inverting the praxis according to which it is humans who usually evaluate technology, and it seems that we might be inverting this order and, more often than not, becoming the object of evaluation, not by other humans, but exclusively by the machines.

In the book, Bad Call, its authors argue that judging has nothing to do with accuracy (something machines are better at than humans), but with justice, which is understood as a reconciliation of what people see while watching sport on TV with what judges observe on the field where the game takes place [33]. In other words, justice, in this sense, is finding an agreement among differences of what human eyes-those of fans and those of judges-have seen. Thanks to technological disruptions, the sport is no longer what human eyes see, but what tools show us: a reality based not on human but on artificial vision. However, if this reality is not visible for us, should we consider it to be more real than what we see? That is to say, a human eye cannot catch a millimetric accuracy of where the ball fell, but maybe it does not even have to? This brings us back to the previously advanced idea that sport is of humans for humans, with all human limitations that come therewith, and judges-not AI-are the best humans to tell the public what is happening in the field.

\subsection{Involving or Pinwheeling the Fans}

Perhaps the community that embraced the technological innovation with biggest gusto is the fans. We have seen that positive technological experience increases sports consumption both inside and outside the stadium [19]. However, if we look closer at this data, we can see that the increase in sports consumption is mainly online: $66 \%$ increased their sport consumption on TV and $60 \%$ in streaming and following teams/players online and through social media, although an increase in stadium attendance can also be observed.

All this sport fandom turned into (digital) sport consumption then brings forward already widely discussed risks related to profiling, digital manipulation, personal data protection, and consumerism as such. For instance, the aforementioned research shows that the more sport is technologically-enhanced, more people consume it. Does it mean that people enjoy sport more or that the technologies are being used to create false needs of sports consumption in people? Moreover, where do the sport values-fairness, dedication, sacrifice-fit in on the shelves of the sport supermarket? Have sport values turned into brands? The overall question is whether being a fan means to be a consumer of sport or whether there is something more to it? How is this continuously growing consumption of sport impacting the quality of human lives and human flourishing?

In addition, and in case being a fan means being a consumer of sport, what about ethical consumerism? There is not much research on ethical consumerism and sports fandom, yet as we are moving towards a more sustainable and more environmentally-conscious model of society, these questions need to be addressed.

However, we should not paint the (disruptive) technologies used to increase fandom in negative colors only. Coming back to VR, we have to ask what kind of ethical implications technologicallyimproved visual, auditive, and cognitive sport experiences could bring to the public. For instance, what kind of impact-beyond enjoyment and pleasure, higher heartbeat rate, and (probably) stress caused if one's team is losing-could VR produce?

To answer the abovementioned question, we need to look at recent research that shows the positive impact of VR on peoples' attitudes towards human rights [34]. Indeed, we discover that to immerge oneself into other peoples' reality helps to become more aware and conscious about others' experiences, and consequently become more sensible to other peoples' particular circumstances and needs. In the world of sport, this could turn into a deeper and more emphatical relationship between the fans and the professional athlete. Indeed, paradoxically, it would also mean a humanization of professional sports, where the athletes many times are not seen as human, but more as gods, and the experience of sport is dehumanized to the extent that the whole competition looks like a video game. Therefore, thanks to VR, many fans could put themselves in the shoes of their sports idols, and discover that these shoes are not as comfortable as they seem from afar. Besides a positive contribution to one's empathy and emotional intelligence, in practical terms, it could also mean an increased social support 
for professional athletes' rights. Indeed, in 2017, the main player associations of the world have issued "The Universal Declaration of Player Rights" (Available online: https://www.uniglobalunion.org/sites/ default/files/files/news/udpr_development_14_dec_17_v1.pdf (accessed on 24 August 2020).) that develops a human rights debate within the framework of "highly skilled yet short term and precarious [ ... ] athletic career." VR could be used to show this human-less fancy and more fragile-side of professional sport and make more people understand that professional sport is not only about medals, fame, and money.

\section{Conclusions}

In the previous part, I have asked some very important questions that should be considered before disruptive technologies are embedded within the sport ecosystem too deeply to be questioned.

Some additional observations emerge after going through these narratives of how disruptive technologies interact with the sport ecosystem: First of all, the overview of these technologies suggest that the only element which could not be substituted by technological means are fans. That is to say that we could turn the athlete into a cyborg and use AI to train and judge her, but we cannot imagine non-humans watching and enjoying the sport competition. From this perspective then, the most human part of the sport ecosystem is fans, who, as already mentioned above, are being turned into consumers of sport.

Looking at it differently and challenging the idea that sport is done by humans for humans, we could also argue that the process of cyborgization of fans is also underway-a thought experiment could help imagine a scenario where all four elements of the sport ecosystem shift to more cyborg-based versions of themselves. For instance, if we take AI and robotics and apply it to running competitions, athletes could run faster thanks to advanced prosthetics, the coaches could have real- time evaluations on an athlete's performance thanks to sensors and Big Data and a direct communication link with the athlete's brain, the judge could have advanced bionic vision to control and judge the speed, and the fans could benefit from a variety of physical robotic enhancements (i.e., wearables that would make them experience what the athlete is experiencing during the competition), and sophisticated algorithms, that thanks to Big Data, could provide them with more information on what has taken place on the running path (such as the athlete's heart beat rate and other statistics). If this scenario would one day turn from speculation into reality, we would assist a new kind of sport: sport done by cyborgs for cyborgs.

Secondly, the elements whose status quo is mostly attacked by disruptive technologies are the coach and judge. The tasks of both of these essential elements of the sport ecosystem is being "vivisected," deconstructed and re-constructed in computational form, enriched with data, metrics, statistics, and other parameters. However, as computation advances, the judge and the coach are left with less space to perform their tasks, and the space they still have is continuously scrutinized and inspected, and any failure is used to advance the idea that the human (coach or judge) is imperfect. Imperfection is a problem, a problem needs a solution, and a solution is technological.

I have argued that to fully comprehend disruptive technologies within the field of sports, we have to look at the whole sport ecosystem and not focus on the athlete only. This is not to say that the athlete is not important-because she definitely is the center of the debate!-however, she is just one of the elements of the sport ecosystem. Therefore, to understand how technology influences sport, we have to adopt a holistic approach that includes different elements rather than focusing on one. The overall idea is that looking at the athlete only, we will never gain the overall vision of how technology disrupts sport, yet we might get this vision if we expand it so as to include other elements of the sport ecosystem, such as the coach, the judge, and the public represented by fans.

To argue my point, I have addressed each of the main elements of the sport ecosystem and showed some of the ways in which disruptive technologies have affected these elements. Afterwards, I addressed some of the ethical implications of these changes. My aim was to show that the repercussions of these technologies are much wider and deeper than it might seem at first glance, both in positive and negative senses. 
There is a feeling for all sports industries in general and the sports ecosystem as addressed in this paper in particular, that the human being-as an athlete in particular, but also as any other element of it-is seen as a means to an end, rather than an end in itself in the Kantian sense. Indeed, the athlete is a driving force for earning money and its failures-injuries, breakdowns, other physical or mental problems-are seen as "malfunctionings" of the engine that cannot stop, and if it stops, it should be "repaired" to be able to get back as quickly as possible. Only if irreparably broken, can the athlete retire, otherwise she has to continue.

The natural question arises whether there is anything pure-purity understood here as uncontaminated by technological advancements-left within sports? The answer is tricky and multi-layered and calls for many more questions. The purpose of this work is to show that in either case-whether we respond to this question with "yes, purity in sport resists technological disruptions" or "no, there is no purity left in sports" — there can be a new kind of (technologically-enhanced) purity that we should strive for as society, as coaches, judges, athletes, and fans; in this sense, purity stands for human and sport values and disruptive technologies should remain tools to achieve-but neither to substitute nor to destroy-them.

Funding: This research received no external funding.

Acknowledgments: The author would like to thank the anonymous reviewers for inspiring and stimulating feedback.

Conflicts of Interest: The author declares no conflict of interest.

\section{References}

1. Pérez Triviño, J.L. The Challenges of Modern Sport to Ethics: From Doping to Cyborgs; Lexington Books: Lanham, MD, USA; Plymouth, UK, 2013.

2. Araújo, C.G.S.; Scharhag, J. Athlete: A working definition for medical and health sciences research. Scand. J. Med. Sci. Sports 2016, 26, 4-7. [CrossRef] [PubMed]

3. Lyle, J. Sports Coaching Concepts: A Framework for Coaches' Behaviour; Routledge: London, UK; New York, NY, USA, 2002.

4. Gantz, W.; Wilson, B.; Lee, H.; Fingerhut, D. Exploring the Roots of Sports Fanship. In Sports Mania: Essays on Fandom and the Media in the 21st Century; Hugenberg, L.W., Haridakis, P.M., Earnheardt, A.C., Eds.; McFarland \& Company Publishers: Jefferson, NC, USA; London, UK, 2008; pp. 63-77.

5. MacKenzie, S. On Sport and Men: Roland Barthes. Can. J. Film Stud. 1997, 6, 75-83. [CrossRef]

6. Pérez Triviño, J.L. Neurodopaje en el Deporte. Gaz. Antropol. 2016, 32, 4. Available online: http://hdl.handle.net/ 10481/43307 (accessed on 25 July 2020).

7. Pérez Triviño, J.L. Gene Doping and the Ethics of Sport: Between Enhancement and Posthumanism. Int. J. Sports Sci. 2011, 1, 1-8. [CrossRef]

8. Carrio Sampedro, A.; Pérez Triviño, J.L. On the Compatibility of Brain Enhancement and the Internal Values of Sport. Sports Ethic Philos. 2017, 11, 307-322. [CrossRef]

9. Lopez Frias, F.J. The Use of Performance-Enhancing Technologies in Sports through Nicolas Agar's “Truly Human Enhancement" Approach. Perform. Enhanc. Health 2018, 6, 44-52. [CrossRef]

10. Lopez Firas, F.J.; McNamee, M. Ethics, Brain Injuries, and Sports: Prohibition, Reform, and Prudence. Sport Ethics Philos. 2017, 11, 264-280. [CrossRef]

11. Zupan, M. Making Skis Strong Enough for Olympians to Race on. The Conversation. 2018. Available online: https://theconversation.com/making-skis-strong-enough-for-olympians-to-race-on-91471 (accessed on 18 August 2020).

12. Can Bacteria in Clothing Really Make an Athlete Faster? Available online: https://design.mit.edu/projects/ puma-biodesign (accessed on 18 August 2020).

13. Roy, B. AI Augmented Sports Revolution. Towards Data Science. 2019. Available online: https:// towardsdatascience.com/ai-augmented-sports-revolution-5c0727ba7004 (accessed on 13 July 2020).

14. Joshi, N. Here's How AIWill Change the World of Sports! Forbes. 2019. Available online: https://www.forbes.com/ sites/cognitiveworld/2019/03/15/heres-how-ai-will-change-the-world-of-sports/\#2a19e5a2556b (accessed on 5 June 2020). 
15. Dugdale, J.H.; Sanders, D.; Myers, T.; Williams, A.M.; Hunter, A.M. A case study comparison of objective and subjective evaluation methods of physical qualities in youth soccer players. J. Sport Sci. 2020, 38, 1304-1312. [CrossRef] [PubMed]

16. International Skating Union. Program Components-Single Skating, Pair Skating, Ice Dance of International Skating Union. Available online: https://www.isu.org/figure-skating/rules/sandp-handbooks-faq/17596program-component-chart-id-sp-2019-20/file (accessed on 20 August 2020).

17. Lee, J. Outlier Aversion in Subjective Evaluation: Evidence from World Figure Skating Championships. J. Sport Econ. 2007, 9, 141-159. [CrossRef]

18. Viana, E.; Bentley, D.J.; Logan-Sprenger, H.M. A Physiological Overview of the Demands, Characteristics, and Adaptations of Highly Trained Artistic Swimmers: A Literature Review. Sports Med. Open 2019, 5, 16. Available online: https://sportsmedicine-open.springeropen.com/track/pdf/10.1186/s40798019-0190-3 (accessed on 2 August 2020). [CrossRef] [PubMed]

19. Capgemini Research Institute. Emerging Technologies in Sports: Reimagining the Fan Experience. Available online: https://www.capgemini.com/wp-content/uploads/2020/01/Infographic-\%E2\%80\%93-Tech-in-Sports. pdf (accessed on 24 August 2020).

20. Canvas8. The Future of Sports Fan. 2016. Available online: https://www.fotball.no/globalassets/dommer/thefuture-sports-fan_spilleregler_english.pdf (accessed on 24 August 2020).

21. Pérez Triviño, J.L. Cyborgsportpersons: Between Disability and Enhancement. Phys. Cult. Sport Stud. Res. 2013, 57, 12-21. [CrossRef]

22. At IMED Hospitals Injury Recovery Can Be Shortened with Regenerative Medicine. Available online: https://www.imedhospitales.com/en/actualidad/at-imed-hospitals-injury-recovery-can-be-shortenedwith-regenerative-medicine/ (accessed on 23 July 2020).

23. Mauri, E. Interview with Rafael Nadal. Aspetar Sports Med. J. 2013, 1, 150-152. Available online: https: //www.aspetar.com/journal/upload/PDF/20131125112050.pdf (accessed on 2 August 2020).

24. Llano Alonso, F.H. Homo Excelsionr. Los Límites Ético-Jurídicos del Transhumanismo; Tirant lo Blanch: Valencia, Spain, 2018.

25. Kious, B.M. Philosophy on Steroids: Why the Anti-Doping Position Could Use a Little Enhancement. Theor. Med. Bioeth. 2008, 29, 213-234. [CrossRef] [PubMed]

26. Savulescu, J.; Foddy, B. Le Tour and Failure of Zero Tolerance: Time to Relax Doping Controls. In Enhancing Human Capacities; Savulescu, J., Meulen, R., Kahane, E., Eds.; Wiley-Blackwell: Chichester, UK, 2011; pp. $304-312$.

27. Geeraets, V. Ideology, Doping and the Spirit of Sport. Sport Ethics Phylos. 2018, 12, 255-271. [CrossRef]

28. Buckland, B. Legal Doping-A Response. The Conversation. 2012. Available online: https://theconversation. com/legal-doping-a-response-8369 (accessed on 22 August 2020).

29. Bantjes, J.; Swartz, L. The Odds Are Stacked against Athletes from Poor Countries in Paralympic Sport. The Conversation. 2017. Available online: https:/theconversation.com/the-odds-are-stacked-againstathletes-from-poor-countries-in-paralympic-sport-70345 (accessed on 18 August 2020).

30. High-Level Expert Group on Artificial Intelligence. Ethics Guidelines for Trustworthy AI. 2019. Available online: https://ec.europa.eu/digital-single-market/en/news/ethics-guidelines-trustworthy-ai (accessed on 4 June 2020).

31. Salzbrenner, S. Are You a Biased Coach? Available online: https://playerdevelopmentproject.com/are-you-abiased-coach/ (accessed on 12 August 2020).

32. International Association of Athletics Federations. Race Walking: A Guide to Judging and Organizing. 2016. Available online: https://www.worldathletics.org/download/download?filename=829b6e82-c23b-407296c2-705a3c7d2ccc.pdf\&urlslug=Race\%20Walking\%202016\%20(A\%20guide\%20to\%20Judging\%20and\% 20Organising) (accessed on 24 August 2020).

33. Collins, H.; Evans, R.; Higgins, C. Bad Call: Technology's Attack on Referees and Umpires and How to Fix It; The MIT Press: Cambridge, MA, USA; London, UK, 2016.

34. Bujic, M.; Salminen, M.; Macey, J.; Hamari, J. “Empathy Machine”: How Virtual Reality Affects Human Rights Attitudes. Internet Res. 2020, 30, 1407-1425. Available online: https://www.emerald.com/insight/ content/doi/10.1108/INTR-07-2019-0306/full/html (accessed on 20 August 2020). [CrossRef]

(C) 2020 by the author. Licensee MDPI, Basel, Switzerland. This article is an open access article distributed under the terms and conditions of the Creative Commons Attribution (CC BY) license (http://creativecommons.org/licenses/by/4.0/). 